\title{
Dynamic changes in cell-surface expression of mannose in the oral epithelium during the development of graft-versus-host disease of the oral mucosa in rats
}

\author{
Hironori Hanada ${ }^{1}$, Jun Ohno ${ }^{1 *}$, Kei Seno ${ }^{2}$, Nobutaka Ota ${ }^{3}$ and Kunihisa Taniguchi ${ }^{1}$
}

\begin{abstract}
Background: The role of cell-surface glycoconjugates in oral mucosal graft-versus-host disease (GVHD) is still unclear, even though molecular changes in the oral epithelium are essential for the pathogenesis of these lesions. In this study, we investigated changes in the binding of mannose (Man)-specific Lens culinaris lectin (LCA) in the oral mucosa of rats with GVHD.

Methods: Lewis rat spleen cells were injected into (Lewis x Brown Norway) $F_{1}$ rats to induce systemic GVHD, including oral mucosal lesions. Tongue and spleen samples were evaluated using lectin histochemistry, immunohistochemistry, Western blotting, transwell migration assays and Stamper-Woodruff binding assays.

Results: Binding of Man-specific LCA expanded to the epithelial layers of the tongue in GVHD-rats. An expansion of LCA binding was related to the increased expression of mannosyltransferase in the oral mucosa. CD8 ${ }^{+}$cells, effector cells of oral mucosal GVHD, expressed mannose-binding protein (MBP) and migrated to the medium containing Man in the transwell migration assay. Adherence of $\mathrm{CD}^{+}$cells to the oral epithelium could be inhibited by pretreating $\mathrm{CD}^{+}$cells with MBP antibody and/or by pretreating sections with Man-specific LCA.

Conclusions: Increased expression of Man on keratinocytes leads to the migration and/or adhesion of $C D 8^{+}$cells in the surface epithelium, which is mediated in part by the MBP/Man-binding pathway during the development of oral mucosal GVHD.
\end{abstract}

Keywords: Graft versus host disease, Lens culinaris lectin, Mannose-binding protein, CD8 ${ }^{+}$lymphocytes

\section{Background}

Graft-versus-host disease (GVHD) is a complication that can occur after a hematopoietic stem cell or bone marrow transplant, which the newly transplanted donor cells attack the transplant recipient's body. GVHD is characterized by selective epithelial inflammation which affects the mucocutaneous organs, gastrointestinal tract, and liver [1]. Both clinical and experimental studies have identified oral mucosa as one of the critical sites affected by GVDH $[2,3]$. Histopathological changes in mucocutaneous GVHD include satellitosis, in which lymphocytes form clusters

\footnotetext{
*Correspondence: johno@college.fdcnet.ac.jp

'Department of Morphological Biology, Division of Pathology, Fukuoka Dental College, Tamura, Fukuoka 2-15-1, Japan

Full list of author information is available at the end of the article
}

around dyskeratotic and/or necrotic keratinocytes (KCs). Lymphocytes, particularly $\mathrm{CD}^{+}$cells, migrate from the perivascular interstitium into the overlying epithelial layer and induce degenerative changes in $\mathrm{KCs}$, suggesting that determining the nature of $\mathrm{KC}$ destruction may aid in understanding the pathogenesis of mucocutaneous GVHD [4]. During this process, expression of specific molecules, such as MHC class II and intercellular adhesion molecule-1 (ICAM-1), occurs in epithelial KCs to interact with effector cells [5-8]. Particularly, increased expression of ICAM-1 on KCs leads to the migration of effector cells into the surface epithelium, which is mediated in part by the ICAM-1/ lymphocyte function-associated antigen-1 (LFA-1) pathway [3]. 
Recent progress in glycobiology has revealed that cell surface glycoconjugates play an essential role in recognition events. Lectin probes have typically been used to detect cell surface glycoconjugates, because lectins are defined as carbohydrate binding proteins other than enzymes or antibodies (Abs) [9]. They are involved in diverse biological processes in many species, such as clearance of glycoproteins from the circulatory system, adhesion of infectious agents to host cells, recruitment of leukocytes to inflammatory sites, and cell interactions in the immune system in conjunction with malignancies and metastasis [9]. Lectin binding is modified during the process of epithelial differentiation and injury stimulation of the skin and oral mucosa [10-13]. Among those lectins, Lens culinaris lectin (LCA), known as a mannose (Man) binder, possesses unique binding specificities, with a biantennary core of 1,6-fucosylated oligosaccharides and glycans of human serum transferrin and $\alpha$ fetoprotein [14]. Cell surface Man is also a ligand for mannose-binding protein (MBP), which functions in opsonization of microorganisms for phagocytes and cellmediated cytotoxicity-antitumor activity [14,15]. These studies have led to the hypothesis that determining changes in Man expression on KCs will aid in understanding the pathogenesis of oral mucosal GVHD. Our approach to this premise has been to focus on cellsurface Man expression by KCs and its interaction with MBP in rat oral mucosal GVHD of the rats. Our study had three goals: (1) to determine cell-surface Man expression by KCs using Man-specific LCA, (2) to investigate whether $\mathrm{CD}^{+}$cells, effector cells in oral mucosa GVHD, migrate to a Man-containing medium, and (3) to determine whether Man expression by KCs mediates binding of MBP-expressing $\mathrm{CD}^{+}$cells to KCs. The results indicate that during the development of oral mucosal GVHD in rats, increased expression of Man by KCs leads to the migration and/or adhesion of $\mathrm{CD} 8^{+}$cells in the surface epithelium, mediated in part by the MBP/ Man-binding pathway.

\section{Methods}

\section{Rats}

Adult female inbred Lewis (LEW, RT $1^{\mathrm{l}}$ ) and Lewis $\times$ Brown Norway $F_{1}$ hybrid $\left(\mathrm{LBNF}_{1}, \mathrm{RTl}^{1 / \mathrm{n}}\right.$ ) rats weighing 250 to 350 grams were purchased from Kyudo Co. (Saga, Japan). The animal studies were conducted in accordance with protocols approved by the Animal Care and Use Committee of Fukuoka Dental College.

\section{Induction of GVHD}

Spleens removed from LEW rats were dissected in Hanks' solution, forced through a stainless steel sieve, and filtered through a nylon mesh (Cell Strainers; BD Biosciences, CA, USA). The cells were washed three times in Hanks' solution and resuspended at $10^{8} / \mathrm{ml}$ in RPMI-1640 medium with $10 \%$ fetal calf serum. Cell viability was determined by trypan blue exclusion analysis. GVHD was induced by a 3-ml intraperitoneal injection of $3 \times 10^{8}$ cells into $\mathrm{LBNF}_{1}$ rats. Untreated $\mathrm{LBNF}_{1}$ rats and $\mathrm{LBNF}_{1}$ rats injected with an equal number of syngeneic $\mathrm{LBNF}_{1}$ splenocytes were used as controls. All rats were weighed daily and carefully observed for clinical signs of disease.

\section{Assessment of GVHD}

Clinical assessment of GVHD was determined by weight loss and the development of cutaneous or mucosal erythema, especially on the ears, nasal mucosa, foot-pads, and lips. Both clinical conditions appeared on day 10 after injection and became severe thereafter. A spleen weight assay was performed at autopsy to confirm the immunological assessment of GVHD. After day 10, the experimental rats showed remarkable splenomegaly as an overexpression of GVHD-related immune response [16]. All control animals survived and appeared healthy.

\section{Tissue preparation}

The whole tongue was excised 1-21 days after injection from five animals in each treatment group. Half of the tongue specimens were fixed in $4 \%$ paraformaldehyde in phosphate-buffered saline (PBS). Paraffin sections $(4 \mu \mathrm{m})$ were then stained with hematoxylin and eosin (H\&E) to examine histopathological changes. The other half was immediately frozen in liquid nitrogen, and serial frozen sections were used for immunostaining, lectin histochemistry, and in vitro adhesion assays.

\section{Lectin histochemistry}

LCA, Ulex europaeus I (UEA-1), and Archis hypogaea (peanut: PNA) were used for detection of $\alpha$-D-Man, $\alpha-$ L-fucose, and galactose $\beta 1,3$ galactosamine, respectively (Vector Laboratories, Inc., Burlingame, CA, USA). LCA binding was detected using the Alexa Fluor 568 - labeled streptavidin biotin method. Acetone-fixed frozen sections were incubated with biotinylated LCA $(25 \mu \mathrm{g} / \mathrm{ml}$; Vector Laboratories) for $30 \mathrm{~min}$ and Alexa Fluor 568labeled streptavidin (1:400; Molecular Probes, Eugene, OR, USA) for $30 \mathrm{~min}$ at room temperature. Histochemical controls substituted unconjugated LCA for the LCA-biotin conjugate and reaction with biotinylated LCA inactivated by its specific sugar inhibitor (D-mannose, 2 mM; EY Laboratories, Inc., San Mateo, CA, USA).

\section{Immunohistochemistry}

Abs used in this study were as follows: (a) a rabbit polyclonal Ab against ALG11, reactive with mannosyltransferase (1:300; Novus Biologicals, Littleton, CO, USA), (b) a rabbit polyclonal $\mathrm{Ab}$ against LMAN2, reactive with 
MBP 2 (1:100; Aviva Systems Biology, San Diego, CA, USA), (c) a mouse monoclonal Ab against 1A29, reactive with ICAM-1 (1:100; Cederlane Lab., Ontario, Canada), and $(\mathrm{d})$ a mouse monoclonal $\mathrm{Ab}$ against $\mathrm{OX}-8$, reactive with CD8 (1:100; Cederlane Lab.). Acetone-fixed frozen sections were first incubated with normal rabbit serum to decrease nonspecific binding and then reacted with one of the Abs, overnight at $4^{\circ} \mathrm{C}$. Sections were then incubated with alkaline phosphatase-conjugated antirabbit $\mathrm{Ab}$ or anti-mouse Ab (1:150 dilution; DakoCytomation, Tokyo, Japan) for $45 \mathrm{~min}$ at room temperature. Immunohistochemical reactions were visualized using 5-bromo-4-chloro-3-indolyl phosphate/ nitro blue tetrazolium chloride solution (BCIP/NBT solution; DakoCytomation). As a control, sections were treated with normal rabbit IgG instead of the first set of Abs.

\section{Western blotting}

Total protein was extracted from spleen and tongue specimens in control or GVHD rats using ice-cold cell lysis buffer $(20 \mathrm{~m} \mathrm{M}$ Tris- $\mathrm{HCl}, \mathrm{pH}$ 7.5; $150 \mathrm{mMNaCl} ; 1 \mathrm{mM}$ ethylenediaminetetraacetic acid [EDTA]; $1 \mathrm{mM} \mathrm{Na} \mathrm{EDDA}_{2}$ $1 \mathrm{mM}$ ethylene glycol tetraacetic acid; $1 \%$ [v/v] Triton-X 100; $2.5 \mathrm{mM}$ sodium pyrophosphate; $1 \mathrm{mM} \beta$-glycerophosphate; $1 \mathrm{mM} \mathrm{Na}_{3} \mathrm{VO}_{4}$; and $1 \mu \mathrm{g} / \mathrm{ml}$ leupeptin and phenylmethylsulfonyl fluoride). Equal amounts of protein $(20 \mu \mathrm{g})$ were separated by sodium dodecyl sulfate-polyacrylamide gel electrophoresis (SDS-PAGE; 12\% separating gel). After electrophoresis, proteins were transferred to polyvinylidene difluoride membranes (Bio-Rad Laboratories, Tokyo, Japan). The blots were blocked with $1 \%$ casein in Tris-buffered saline (TBS) containing 0.1\% Tween-20 (TBS-T) for $1 \mathrm{~h}$ at room temperature and then incubated with primary antibodies overnight at $4^{\circ} \mathrm{C}$. Primary Abs against LMAN2 (described earlier) and $\beta$-actin (Sigma-Aldrich) were used. Membranes were washed in TBS-T and incubated with secondary horseradish peroxidase-labeled $\mathrm{Ab}$ for $1 \mathrm{~h}$ at room temperature. Bound $\mathrm{Ab}$ complexes were detected by enhanced chemiluminescence (BioRadLaboratories).

\section{Isolation of $\mathrm{CD}^{+}$cells from the spleens of GVHD- mediated rats}

$\mathrm{CD}^{+}$cells from GVHD rats were used in transwell migration assays and Stamper-Woodruff binding assays. Lymphocytes were teased from spleen, exhibiting splenomegaly, of GVHD rats and suspended in RPMI-1640 medium at $4^{\circ} \mathrm{C}$. The cells were dispersed by rapid, in-out pipetting, and the cell clumps were removed by passage through a nylon mesh (Cell Strainers; BD Biosciences). The resultant single-cell suspension was washed three times in the same medium and resuspended at a concentration of $3 \times 10^{7}$ mononuclear cells $/ \mathrm{ml}$. CD $8^{+}$cells from the suspension were isolated by magnetic bead purification using Miltenyi CD8a microbeads according to the manufacturer's protocol (Miltenyi Biotec, Tokyo, Japan).

\section{Transwell migration assay for effector cells}

Migration of $\mathrm{CD}^{+}$cells from the GVHD-spleen were evaluated in a transwell ${ }^{\bullet}$ insert system in which the top and bottom wells were separated by polycarbonate membrane (3- $\mu \mathrm{m}$ pore size; Corning, NY, USA). $\mathrm{CD}^{+}$cells, preincubated or not with anti-MBP Ab $(50 \mu \mathrm{g} / \mathrm{ml})$, were seeded at a density of $5 \times 10^{4}$ cells /well onto $3-\mu \mathrm{m}$ transwell inserts. The lower chamber was filled with $500 \mu \mathrm{l}$ RPMI medium only or medium containing Man (2 mM), a mixture of Man and LCA $(50 \mu \mathrm{g} / \mathrm{ml})$, or galactose (Gal, $2 \mathrm{mM}$; EY Laboratories). The cells were incubated for $4 \mathrm{~h}$ at $37^{\circ} \mathrm{C}\left(5 \% \mathrm{CO}_{2}\right)$ and then stained with Diff-Quik (Sysmex Corp., Hyogo, Japan). Migration activity was evaluated as the percent migration of cells from the upper chamber of the transwell insert to the lower chamber in three high power fields $(100 x)$ per well. The experiment was performed in triplicate.

\section{Stamper-Woodruff binding assay (SWBA)}

Stamper-Woodruff-type frozen-section assays were performed as described previously [3]. Briefly, aliquots containing $2.5 \times 10^{5}$ isolated $\mathrm{CD}^{+}$cells in $200 \mu \mathrm{l}$ of RPMI-1640 medium were added to freshly cut $(8 \mu \mathrm{m})$ frozen sections of the tongue obtained from rats in the control and GVHD groups. The sections were agitated on a rotary shaker $(60 \mathrm{rpm})$ for $60 \mathrm{~min}$ at room temperature. Next, the cell suspension was carefully decanted, and cells adhering to sections were fixed with $2.5 \%$ glutaraldehyde in PBS for 5 min. Slides were then washed in PBS and stained with $0.5 \%$ toluidine blue. The number of adherent $\mathrm{CD}^{+}$cells was determined by light microscopy examination of fields at $200 \times$ magnification (Each high-power field represented approximately $400 \mu \mathrm{m}$ of oral epithelium). The number of $\mathrm{CD}^{+}$cells attached directly over KCs (but not in the cornified layer) was counted. Several blocking experiments were performed as follow: (a) frozen sections of tongue from GVHD rats were incubated with $25 \mu \mathrm{g} / \mathrm{ml}$ of LCA, PNA or UEA-I for $30 \mathrm{~min}$ at room temperature following a brief wash with PBS, and then added to lymphocytes; (b) $\mathrm{CD}^{+}$cells were preincubated with $50 \mu \mathrm{g} / \mathrm{ml}$ of MBP Ab for $30 \mathrm{~min}$ at room temperature, before the entire reaction mixture was transferred onto frozen sections of the GVHDtongues; (c) the two approaches were used simultaneously, i.e., $\mathrm{CD}^{+}$cells were treated with MBP Ab and the tissue sections were treated with MBP. Results are calculated as the percentage of binding relative to control lymphocytes and tissue sections exposed to buffer alone. 


\section{Statistical analysis}

Statistical analysis was performed with one-way analysis of variance (ANOVA) and Scheffe's multiple comparison tests to determine statistical differences among the samples. Data are presented as the mean \pm standard deviation (SD) and $P$ values of $<0.05$ were considered statistically significant.

\section{Results}

Oral mucosal GVHD is characterized by ICAM-1 expression and $\mathrm{CD} 8^{+} \mathrm{T}$-cell infiltrates

First we examined whether immunohistochemical characteristics could be detected in the oral mucosa during the development of GVHD. In untreated control tongues, no histological changes were seen with $H \& E$ staining (Figure 1a). ICAM-1 expression was restricted to endothelial and perivascular cells of blood vessels (Figure 1c). Only a few $\mathrm{CD}^{+}$cells were observed in the lamina propria and oral epithelium (Figure 1e). The results were the same in tissue sections taken from experimental rats 8 days after injection. However, 10 days after induction of GVHD in $\mathrm{LBNF}_{1}$ rats, both histological and immunohistochemical changes were observed in the tongues. $H \& E$ staining revealed lesions typical of acute mucocutaneous GVHD, indicating eosinophilic cytoplasmic degeneration and necrosis of epithelial KCs (the so-called satellitosis) resulting from intraepithelial infiltration of lymphocytes (Figure 1b). ICAM-1 expression was observed in the basal to spinous layers of the epithelium (Figure 1d) and the number of $\mathrm{CD}^{+}$cells increased in the lamina propria of the tongue (Figure 1f). Furthermore, these cells were infiltrated into the surface epithelium where epithelial KCs were stained with anti-ICAM-1 Ab.
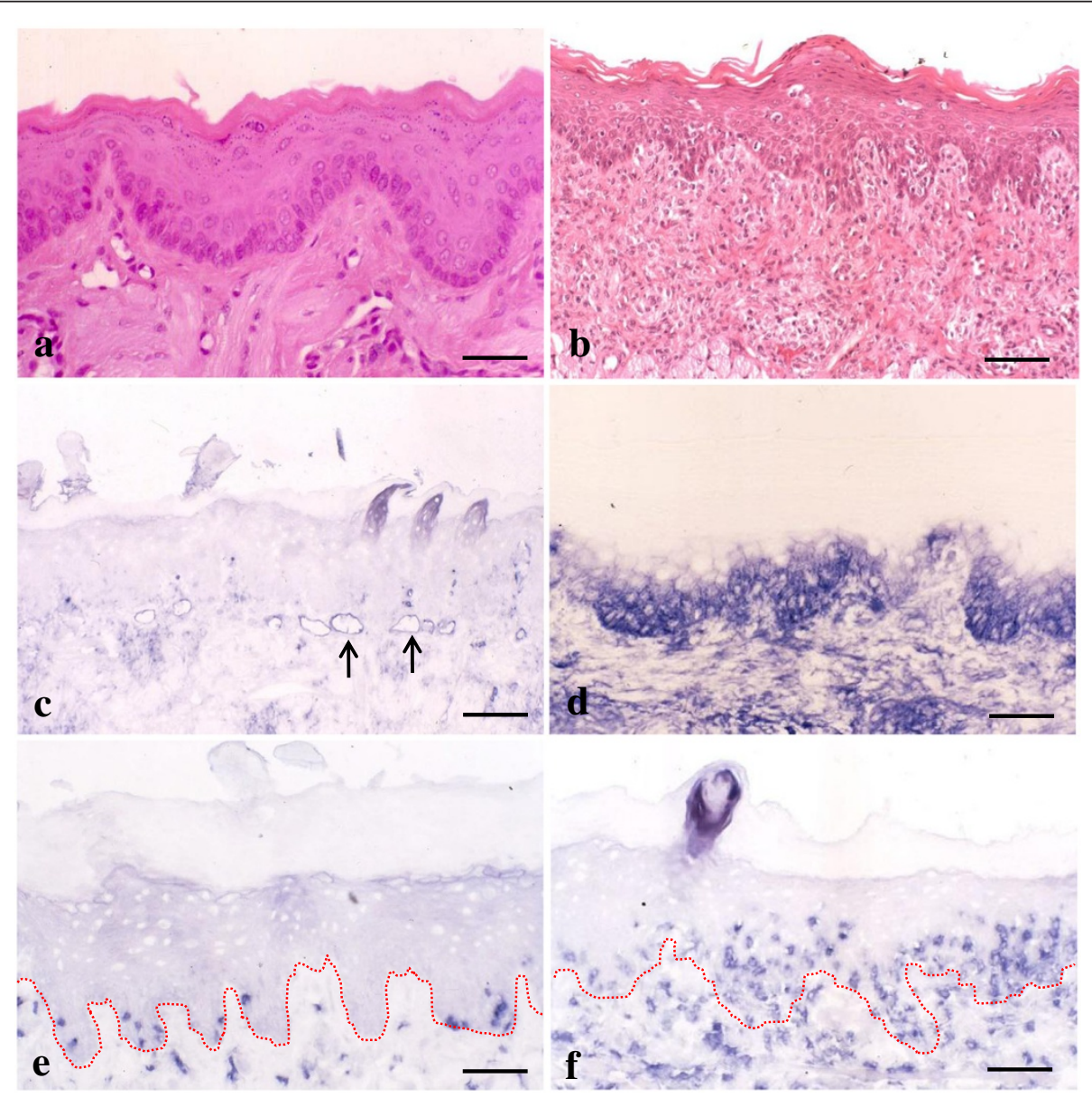

Figure 1 Immunohistochemical expression of intercellular adhesion molecule-1 (ICAM-1) and CD8 ${ }^{+}$in graft-versus-host disease (GVHD)-related oral mucosa. $\mathbf{a}$ and $\mathbf{b}$ : No obvious changes are observed in hematoxylin and eosin (H\&E)-stained control tongue sections (a). In tongue tissue sections from GVHD rats, epithelial destruction is observed (b). $\mathbf{c}$ and $\mathbf{d}$ : In tongue specimens from control rats, ICAM-1 is expressed only in the vascular slits (arrows) (c). Epithelial ICAM-1 expression is observed in the basal to spinous layers of the oral mucosa from GVHD rats (d). e and f: Only a few $\mathrm{CD}^{+}$cells are found in the control (e). In the GVHD rats, increased numbers of CD8 ${ }^{+}$cells are observed in both lamina propria and surface epithelium (f). The dotted line shows a junction between the surface epithelium and lamina propria of the tongue. Bar $=100 \mu \mathrm{m}$. 


\section{Alterations in LCA binding in oral mucosal GVHD}

To elucidate whether histochemical expression of cellsurface Man on epithelial KCs is affected by the development of GVHD, we examined LCA staining in the tongues of control and GVHD rats. LCA binding was restricted to the cell surface of the basal to parabasal KCs in the surface epithelium of the tongues from control rats (Figure 2a). The same staining pattern was shown in tissue sections taken from experimental rats eight days after injection. In contrast, the level of LCA staining extended to the spinous layers of the surface epithelium 10 days after injection, indicating that oligosaccharides on $\mathrm{KCs}$ could be modified during the development of GVHD (Figure 2b). Furthermore, the extension pattern of LCA staining was identical to that of ICAM-1 expression.

\section{Increased expression of mannosyltransferase complex in oral mucosal GVHD}

We next examined the immunohistochemical expression of mannosyltransferase complex, using ALG11 Ab, in tongues from both control and GVHD rats, to elucidate

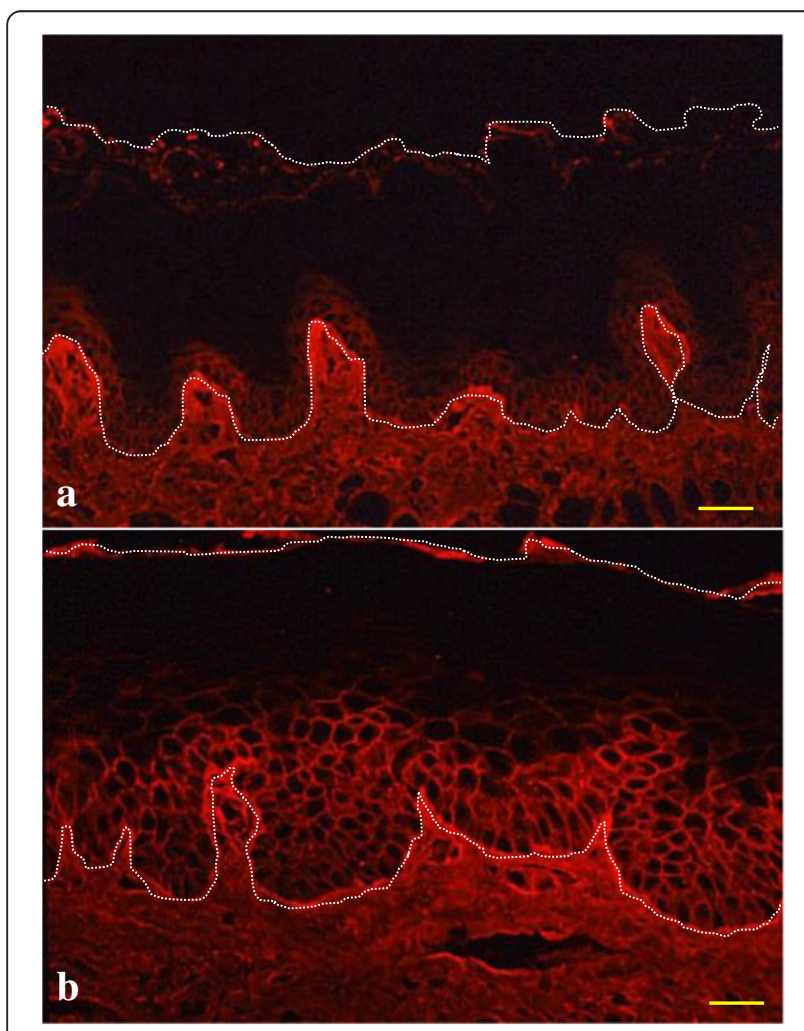

Figure 2 Lens culinaris lectin (LCA) binding in graft-versus-host disease (GVHD) oral mucosa. LCA binding occurs on the cell surface of basal to parabasal cells in control tongues (a). Staining extends to the spinous layers of the surface epithelium in GVHD rats (b). The white dotted line circumscribes the surface epithelial layer of the tongue. Bar $=100 \mu \mathrm{m}$. whether the mannosyltransferase could be responsible for the addition of Man on the oligosaccharides in KCs during the development of GVHD. In normal tongue, ALG11 bound weakly and/or faintly to basal and parabasal KCs of the surface epithelium (Figure 3a). Reactive sites with ALG11 extended to the cytoplasm of KCs in the spinous layers of the surface epithelium in the tongues of GVHD rats (Figure $3 \mathrm{~b}$ ). The reactive range with ALG11 seemed to be identical to that of LCA binding, suggesting that increased expression of mannosyltransferase in the epithelial layers may be related to extensive binding of LCA.

\section{MBP /Man-binding pathway induces $\mathrm{CD}^{+}$cell migration in vitro}

To elucidate if migration of $\mathrm{CD}^{+}$cells is mediated by the MBP/Man-binding pathway, we examined MBP expression in the tongues of GVHD rats and the transwell migration assay for $\mathrm{CD}^{+}$cells. First, we examined immunohistochemical detection of MBP in tissue sections of the tongue from the GVHD-rats. $\mathrm{MBP}^{+}$infiltrating cells were observed in both the upper lamina propria and surface epithelium of the tongues (Figure 4a). We also examined protein expression of MBP in the tongues and spleen of control and GVHD rats by Western blot analysis. As shown in Figure 4b, the amount of MBP accumulation was markedly increased in both the tongue and spleen of GVHD rats. In contrast, expression of MBP protein was faint or negative in both the tongue and spleen of control rats (Figure $4 \mathrm{~b}$ ). These results suggest that MBP may be induced on GVHD-related effector cells and MBP on effector cells may react against cell-surface Man of KCs in the tongues of GVHD rats. To test this hypothesis, we next performed transwell migration assays for effector cells. As shown in Figure 5, the percent migration of $\mathrm{CD}^{+}$cells to Man increased drastically $(77.9 \pm 4.6)$ compared with control $(1.7 \pm 0.6)$. The migration percent of $\mathrm{CD}^{+}$cells became lower in the lower chamber containing Man and LCA $(8.3 \pm 0.7)$ and Gal $(1.5 \pm 0.7)$. Furthermore, the $\mathrm{CD}^{+}$cell migration to Man decreased drastically $(5.6 \pm 0.4)$ when the cells were pre-incubated with anti-MBP Ab. These results indicate that migration of $\mathrm{CD}^{+}$cells to Man is mediated by the MBP/Man-binding pathway.

\section{Anti-MBP Ab and LCA inhibit adhesion of $\mathrm{CD}^{+}$cells to $\mathrm{KCs}$ in tongue specimens from rats with GVHD}

In the rat GVHD model, effector cells can bind to lesional KCs by the ICAM-1/LFA-1 pathway [3]. We performed SWBA using $\mathrm{CD}^{+}$cells and/or oral epithelial cells taken from rats with GVHD, to provide evidence of a direct role of the MBP/Man-binding pathway in the binding of $\mathrm{CD}^{+}$cells to epithelial KCs. Pretreatment of the tissue sections prepared from the oral mucosa with 


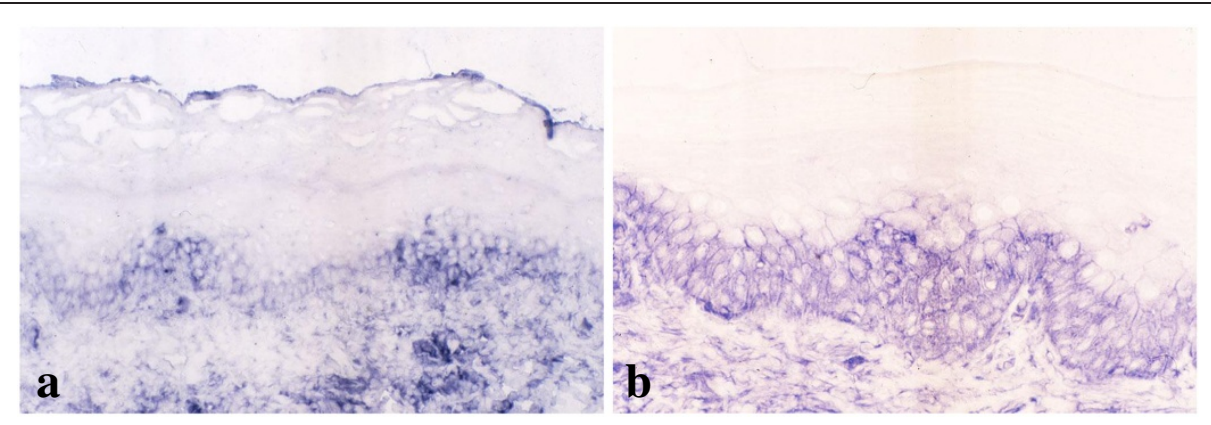

Figure 3 Immunohistochemical detection of mannosyltransferase complex in graft-versus-host disease (GVHD)-affected oral mucosa. ALG11, antibody (Ab) of mannosyltransferase complex, is weakly and faintly reactive in basal and parabasal epithelial cells of control tongues (a). In contrast, staining with ALG11 extends to keratinocytes (KCs) in the spinous layers of tongues from GVHD rats (b). Bar $=100 \mu \mathrm{m}$.

PNA and UEA-I had no effect, whereas LCA decreased lymphocyte adhesion by $42.3 \%$ of the control value (Figure 6). When lymphocytes from rats with GVHD were incubated with anti-MBP Ab, lymphocyte adhesion to epithelial KCs was $42.7 \%$ of the control value (Figure 6). When the two approaches were applied simultaneously, i.e., when the lymphocytes were treated with anti-MBP $\mathrm{Ab}$ and the tissue sections were treated with LCA, lymphocyte adhesion was decreased to $<40 \%$ of the control value (Figure 6). These results indicate that the adhesion of $\mathrm{CD} 8^{+}$cells to epithelial $\mathrm{KCs}$ is mediated in part by the MBP/Man-binding pathway.

\section{Discussion}

In this study we use the haploidentical allogeneic $F_{1}$ hybrid rat model to elucidate the role of cell-surface expression of Man residues by $\mathrm{KCs}$ in GVHD. Although this model does not directly represent clinical hematopoietic cell transplantation in human, it provides a convenient and genetically well-defined system from which to gain insights into the mechanisms underlying immune-mediated tissue damages of host epithelial tissue by studying the in vivo interactions between $\mathrm{KCs}$ and lymphocytes [17]. We present three lines of evidence to support the conclusion that cell-surface expression of Man by KCs plays a role in the migration and/or adhesion of $\mathrm{CD}^{+}$cells in the epithelium during the development of GVHD. First, a lectin histochemical approach confirmed that the cell-surface expression of Man by KCs was up-regulated in the development of GVHD. Second, protein expression and transwell migration results indicated that $\mathrm{CD} 8^{+}$cell migration to Man was related to an interaction between MBP and Man. Third, $\mathrm{CD}^{+}$cell adhesion of the mucosal surface epithelium was mediated by the MBP/Man-binding pathway as revealed using SWBA.

An up-regulation of LCA binding on the cell surface of KCs indicates that the cell-surface expression of Man is modified during the development of oral mucosal GVHD. In mucocutaneous GVHD, specific molecular changes occur in KCs to allow lymphocyte migration into the surface epithelial layer $[7,8,18]$. A previous study has reported that the induction of ICAM-1 expression on $\mathrm{KCs}$ leads to the migration of $\mathrm{CD}^{+}$cells into the epithelium and that this process is mediated in part by the ICAM-1/LFA-1 pathway [3]. The results presented here

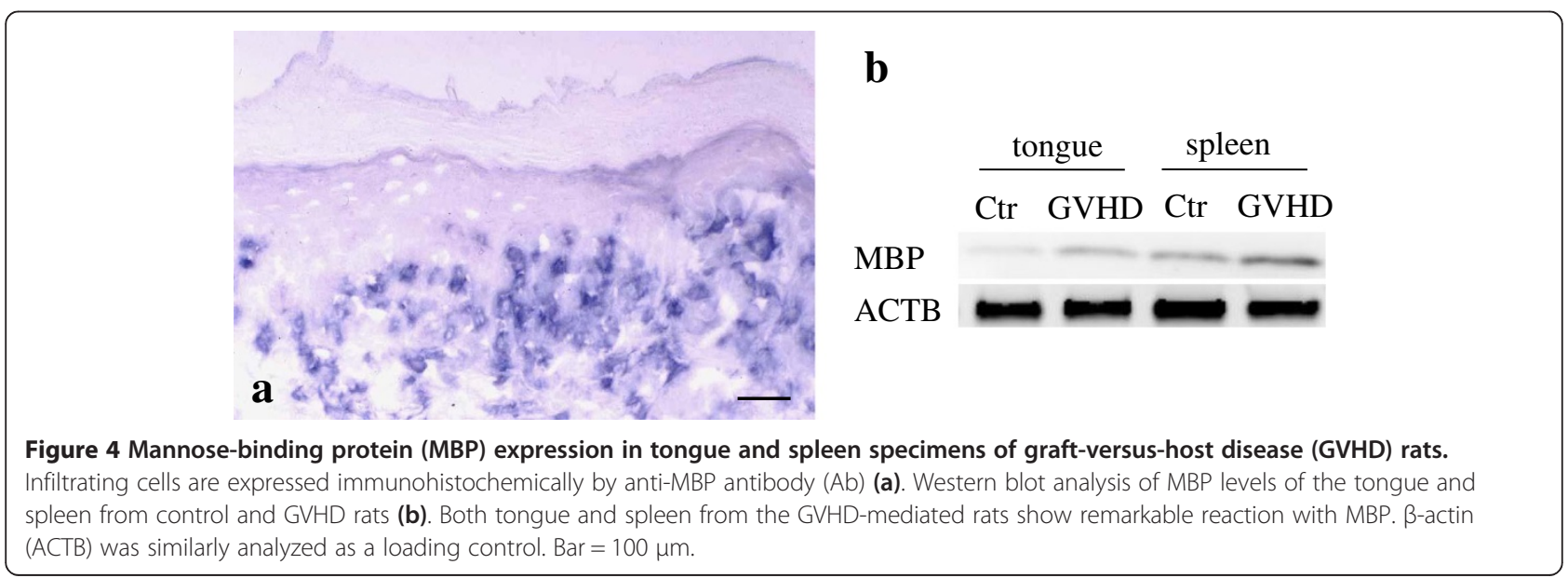




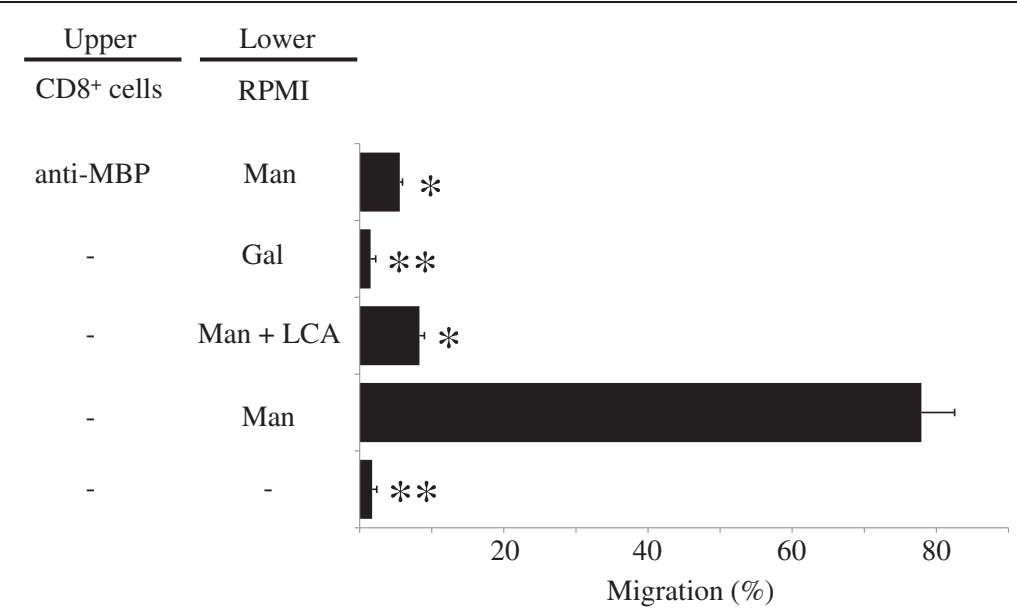

Figure 5 Induction of mannose (Man) to $\mathrm{CD}^{+}$cell migration. $\mathrm{CD} 8^{+}$cell migration was examined by the transwell migration assay. Man, Man with Lens culinaris lectin (LCA), or galactose was placed in the lower chamber well. The wells of the upper chamber receive isolated CD ${ }^{+}$cells, pretreated or not with anti-mannose-binding protein (MBP) antibody (Ab). RPMI was used as a negative control. The figure represents results of three different experiments expressed as mean \pm standard deviation. Same symbols show no statistically significant differences. Others,

significantly different at $P<0.05$.

provide additional support for molecular changes in $\mathrm{KCs}$ during the development of oral mucsal GVHD. The immunohistochemical study of anti-ALG11 Ab reported here shows that $\mathrm{Ab}$ reactive sites also expand to spinous layers in the surface epithelium in the GVHD tongue. ALG11 is known as alpha-1,2-mannosyltransferase in Nlinked glycoprotein and is localized to the cytosolic side of the endoplasmic reticulum in basal cells of normal squamous epithelia [19]. These findings suggest that the extensive expression of mannosyltransferase complex may be indirectly responsible for the upregulation of Man expression on the cell surface of KCs in the GVHD tongue. Future work will address why the expression of mannosyltransferase complex and Man expand during the development of GVHD.

Immunohistochemical and Western blot analyses presented here reveal that effector cells of GVHD show the expression of MBP using LMAN2 $\mathrm{Ab}$, in addition to

Lectin and $\mathrm{Ab}$ pretreatment of

lymphocytes oral mucosa

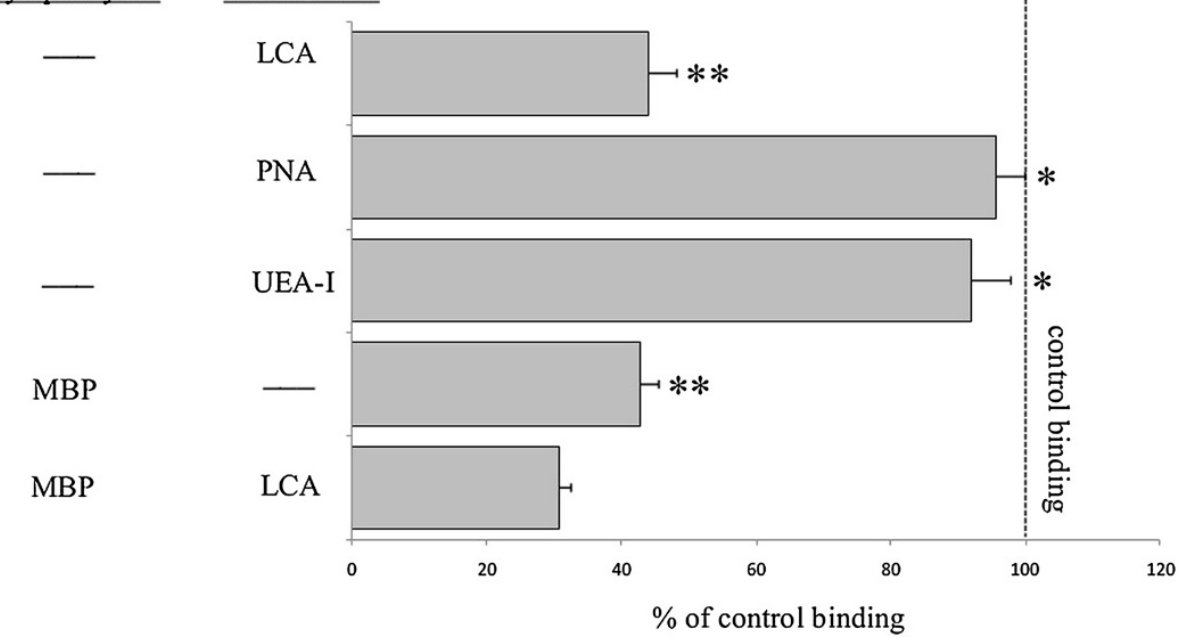

Figure 6 Effect of lectins and anti-mannose-binding protein (MBP) antibody (Ab) on $\mathrm{CD}^{+}$cell adhesion to the oral epithelium in GVHD. Adhesion of $\mathrm{CD}^{+}$cells to the oral keratinocytes (KCs) were investigated by Stamper-Woodruff binding assay (SWBA). Binding of CD8 ${ }^{+}$cells was significantly decreased when the cells were pretreated with anti-MBP Ab, as well as when epithelia were pretreated with Lens culinaris lectin $(\mathrm{LCA})$. The figure represents the results of three different experiments and expressed as mean \pm standard deviation. Same symbols show no statistically significant differences. Others, significantly different at $P<0.05$. 
CD8. MBP, also called mannan-binding protein or mannan-binding lectin, is a $\mathrm{Ca}^{+}$-dependent (C-type) animal lectin [20-22]. A recent study revealed that this protein could display a specific effect on $\mathrm{T}$ cell activation [23]. MBP preferentially binds to carbohydrates terminated with Man, $\mathrm{N}$-acetylglucosamine, or fucose [24]. Therefore, MBP-expressing lymphocytes seem to interact with Man-expressing KCs in oral mucosal GVHD. Our results of the transwell migration assay indicate that the migration of the MBP-expressing $\mathrm{CD}^{+}$cells is accelerated by medium containing Man. $\mathrm{CD} 8^{+}$cell migration was inhibited by a mixture of Man and LCA and pretreatment of cells with LMAN2 Ab, indicating that MBP on $\mathrm{CD}^{+}$cells recognized Man specifically. These results suggest that the migration of effector cells, $\mathrm{CD}^{+}$lymphocytes, to Man-expressing KCs may be mediated by an interaction between MBP and Man.

$\mathrm{CD}^{+}$cell-adhesion to epithelium stained with Manspecific LCA was demonstrated using SWBA. Thus, the binding of $\mathrm{CD}^{+}$cells on the surface epithelium during the development of GVHD increases along with Man expression and correlates with disease progression. These results are consistent with in vivo observations of $\mathrm{KCs}$ expressing Man-specific LCA to adhere to $\mathrm{CD}^{+}$cells during the progression of GVHD. In an adhesion process, $\mathrm{MBP}$ on $\mathrm{CD}^{+}$cells plays an important role as an adhesive factor of Man-expressing KCs during the development of GVHD. Furthermore, the results of LCA and Ab-blocking experiments supported the idea that $\mathrm{MBP} / \mathrm{Man}$ interactions account for the binding of $\mathrm{CD}^{+}$ cells. Thus, LMAN2 Ab, LCA, or LMAN2 Ab together with LCA, blocked all $\mathrm{CD}^{+}$cell-binding compared with lecitns recognizing unrelated Man residues. Our previous study revealed that the induction of ICAM-1 expression on $\mathrm{KCs}$ led to the adhesion of $\mathrm{CD}^{+}$cells to the surface epithelium and that this was mediated in part by the ICAM-1/LFA-1 pathway [3]. The MBP/Man interactions presented here belong to another adhesive pathway for the migration and adhesion of effector cells in the surface epithelium during the development of oral mucosal GVHD.

In summary, these results define the role of Man expression on KCs during the development of GVHD as inducing migration of MBP-expressing $\mathrm{CD}^{+}$cells into the oral epithelium where they adhere to KCs. The upregulation of Man expression on KCs is undoubtedly a key step in the pathogenesis of oral mucosal GVHD.

\section{Conclusion}

An increased expression of Man on KCs leads to the migration and/or adhesion of $\mathrm{CD} 8^{+}$cells in the surface epithelium and this is mediated in part by the MBP/ Man pathway during the development of oral mucosal GVHD.

\section{Abbreviations}

ACTB: $\beta$-actin; Ab: Antibody; GVHD: Graft-versus-host disease;

H\&E: Hematoxylin and eosin; ICAM-1: Intercellular adhesion molecule-1; KCs: Keratinocyte; LCA: Lens culinaris lectin; LFA-1: Lymphocyte functionassociated antigen-1; MBP: Mannose-binding protein; Man: Mannose; PBS: Phosphate-buffered saline; SWBA: Stamper-Woodruff binding assay.

\section{Competing interests}

The authors declare that they have no competing interests.

\section{Authors' contributions}

$\mathrm{HH}$ and JO planned the study, performed the experiments and data analysis, and wrote the manuscript. KS and NO performed the lectin staining and helped to draft the manuscript. KT supervised writing of the manuscript. All authors read and approved the final manuscript.

\section{Acknowledgements}

This study was supported in part by a Grant-in-Aid from the Ministry of Education, Culture, Sports, Science and Technology of Japan (\#24390422 and \#25670802 to JO). The authors would like to thank Enago (www.enago.jp) for the English language review.

\section{Author details}

'Department of Morphological Biology, Division of Pathology, Fukuoka Dental College, Tamura, Fukuoka 2-15-1, Japan. ²Department of General Dentistry, Division of General Dentistry, Fukuoka Dental College, Tamura, Fukuoka 2-15-1, Japan. ${ }^{3}$ Department of Oral and Maxillofacial Surgery, Division of Oral Oncology, Fukuoka Dental College, Tamura, Fukuoka 2-15-1, Japan.

Received: 15 October 2013 Accepted: 15 January 2014

Published: 16 January 2014

\section{References}

1. Aractingi S, Chosidow O: Cutaneous graft-versus-host disease. Arch Dermatol 1998, 134:602-612.

2. Woo SB, Lee SJ, Schubert MM: Graft-vs.-host disease. Crit Rev Oral Biol Med 1997, 8:201-216

3. Ohno J, Iwahashi T, Ehara M, Ozasa R, Hanada H, Funakoshi T, Taniguchi K: Induction of epithelial migration of lymphocytes by intercellular adhesion molecule-1 in a rat model of oral mucosal graft-versus-host disease. Histol Histopathol 2011, 26:725-733.

4. Wagner JL, Murphy GF: Graft-vs.-Host Disease, Pathology and pathogenesis of cutaneous graft-vs.host disease. 3rd edition. New York: Marcel Dekker; 2005:229-255.

5. Norton J, Sloane JP: A prospective study of cellular and immunologic changes in skin of allogeneic bone marrow recipients. Relationship to clinical and histologic features of acute graft-versus-host disease. Am J Clin Pathol 1994, 101:597-602.

6. Norton J, Sloane JP: ICAM-1 expression on epidermal keratinocytes in cutaneous graft-versus-host disease. Transplantation 1991, 51:1203-1206.

7. Sloane JP, Elliott CJ, Powles R: HLA-DR expression in epidermal keratinocytes after allogeneic bone marrow transplantation. Relationship to histology, rash, marrow purging, and systemic graft-versus-host disease. Transplantation 1988, 46:840-844.

8. Lampert IA, Suitters AJ, Chisholm PM: Expression of la antigen on epidermal keratinocytes in graft-versus-host disease. Nature 1981, 293:149-150.

9. Ambrosi M, Cameron NR, Davis BG: Lectins: tools for the molecular understanding of the glycocode. Org Biomol Chem 2005, 3:1593-1608.

10. Ohno J, Iwahashi T, Ehara M, Taniguchi K: Alterations in PNA binding of keratinocytes in oral keratosis. Biotech Histochem 2011, 86:168-173.

11. Brabec RK, Peters BP, Bernstein IA, Gray RH, Goldstein IJ: Differential lectin binding to cellular membranes in the epidermis of the newborn rat. Proc Natl Acad Sci USA 1980, 77:477-479.

12. Ohno J, Fukuyama K, Epstein WL: Dynamic changes of cell-surface glycoconjugates in human palmar epidermis following friction-blisters. Cell Tissue Res 1989, 258:403-408.

13. Nemanic MK, Whitehead JS, Elias PM: Alterations in membrane sugars during epidermal differentiation: visualization with lectins and role of glycosidases. J Histochem Cytochem 1983, 31:887-897. 
14. Maupin KA, Liden D, Haab BB: The fine specificity of mannose-binding and galactose-binding lectins revealed using outlier motif analysis of glycan array data. Glycobiology 2012, 22:160-169.

15. Uemura K, Saka M, Nakagawa T, Kawasaki N, Thiel S, Jensenius JC, Kawasaki T: L-MBP is expressed in epithelial cells of mouse small intestine. J Immunol 2002, 169:6945-6950.

16. Grant D, Zhong R, Gunn H, Duff J, Garcia B, Keown P, Wijsman J, Stiller C: Graft-versus-host disease associated with intestinal transplantation in the rat. Host immune function and general histology. Transplantation 1989, 48:545-549.

17. Thomas DW, Matthews JB, Prime SS: Mucosal cell-mediated immunological changes associated with experimental graft-versus-host disease. J Oral Pathol Med 1996, 25:145-150.

18. Sviland L, Pearson AD, Eastham EJ, Green MA, Hamilton PJ, Proctor SJ, Malcolm AJ: Class II antigen expression by keratinocytes and enterocytes-an early feature of graft-versus-host-disease. Transplantation 1988, 46:402-406.

19. Rind N, Schmeiser V, Thiel C, Absmanner B, Lubbehusen J, Hocks J, Apeshiotis N, Wilichowski E, Lehle L, Korner C: A severe human metabolic disease caused by deficiency of the endoplasmatic mannosyltransferase hALG11 leads to congenital disorder of glycosylation-Ip. Hum Mol Genet 2010, 19:1413-1424

20. Kawasaki T, Etoh R, Yamashina I: Isolation and characterization of a mannan-binding protein from rabbit liver. Biochem Biophys Res Commun 1978, 81:1018-1024.

21. Sastry K, Zahedi K, Lelias JM, Whitehead AS, Ezekowitz RA: Molecular characterization of the mouse mannose-binding proteins. The mannosebinding protein $\mathbf{A}$ but not $\mathbf{C}$ is an acute phase reactant. J Immunol 1991, 147:692-697.

22. Kawasaki T: Structure and biology of mannan-binding protein, MBP, an important component of innate immunity. Biochim Biophys Acta 1999, 1473:186-195.

23. Benoist $H$, Culerrier R, Poiroux $G$, Segui B, Jauneau A, Van Damme EJ, Peumans WJ, Barre A, Rouge P: Two structurally identical mannosespecific jacalin-related lectins display different effects on human $T$ lymphocyte activation and cell death. J Leukoc Biol 2009, 86:103-114.

24. Weis WI, Drickamer K, Hendrickson WA: Structure of a C-type mannosebinding protein complexed with an oligosaccharide. Nature 1992, 360:127-134.

doi:10.1186/1472-6831-14-5

Cite this article as: Hanada et al:: Dynamic changes in cell-surface expression of mannose in the oral epithelium during the development of graft-versus-host disease of the oral mucosa in rats. BMC Oral Health 2014 14:5.

\section{Submit your next manuscript to BioMed Central and take full advantage of:}

- Convenient online submission

- Thorough peer review

- No space constraints or color figure charges

- Immediate publication on acceptance

- Inclusion in PubMed, CAS, Scopus and Google Scholar

- Research which is freely available for redistribution 